\title{
A high average current DC GaAs photocathode gun for ERLs and FELS
}

\author{
C. Hernandez-Garcia*, T. Siggins, S. Benson, D. Bullard, H. F. Dylla, K. Jordan, C. Murray, G. R. \\ Neil, M. Shinn, and R. Walker, TJNAF, Newport News, VA 23606, USA
}

\section{Abstract}

The Jefferson Lab (JLab) $10 \mathrm{~kW}$ IR Upgrade FEL DC GaAs photocathode gun is presently the highest average current electron source operational in the U.S., delivering a record $9.1 \mathrm{~mA} \mathrm{CW}, 350 \mathrm{kV}$ electron beam with 122 $\mathrm{pC} /$ bunch at $75 \mathrm{MHz}$ rep rate. Pulsed operation has also been demonstrated with $8 \mathrm{~mA}$ per pulse (110 pC/bunch) in $16 \mathrm{~ms}-$ long pulses at $2 \mathrm{~Hz}$ rep rate. Routinely the gun delivers $5 \mathrm{~mA} \mathrm{CW}$ and pulse current at $135 \mathrm{pC} /$ bunch for FEL operations. The Upgrade DC photocathode gun is a direct evolution of the DC photocathode gun used in the previous JLab $1 \mathrm{~kW}$ IR Demo FEL. Improvements in the vacuum conditions, incorporation of two UHV motion mechanisms (a retractable cathode and a photocathode shield door) and a new way to add cesium to the GaAs photocathode surface have extended its lifetime to over 450 Coulombs delivered between re-cesiations (quantum efficiency replenishment). With each photocathode activation quantum efficiencies above $6 \%$ are routinely achieved. The photocathode activation and performance will be described in detail.

\section{INTRODUCTION}

The GaAs DC photocathode gun driving the JLab 10 kW IR Upgrade FEL recently demonstrated $9.1 \mathrm{~mA} \mathrm{CW}$ [1], making this type of gun the leading choice in high average current, high brightness electron beam sources for the development of $100 \mathrm{~mA}$ class injectors for ERLs and FELs [2,3]. Performance, procedures and unique design features of the JLab $10 \mathrm{~kW}$ IR Upgrade FEL DC photocathode gun will be presented.

\section{EXPERIMENTAL LAYOUT}

The Upgrade Cs:GaAs DC photocathode gun is an improved version of the JLab $1 \mathrm{~kW}$ Demo IR FEL gun [4]. Electron pulses are generated by the Cs:GaAs photocathode when it is illuminated with a frequencydoubled, mode-locked Nd:YLF drive laser. The drive laser generates pulses at a maximum repetition rate of 75 $\mathrm{MHz}$ in $\mathrm{CW}$ mode and up to $5 \mathrm{~W}$ of SHG power at 527 $\mathrm{nm}$. A $0.8 \mathrm{~cm}$ diameter aperture truncates the Gaussian laser beam and is focused on the $2.54 \mathrm{~cm}$ diameter photocathode off its electrostatic center to reduce QE degradation of the illuminated area from back-ion bombardment. The temporal profile of the laser pulses is also Gaussian approximately 23 ps rms long. The drive laser intensity is set accordingly with the photocathode $\mathrm{QE}$ to produce $135 \mathrm{pC}$ per electron bunch to meet the beam specifications for the JLab $10 \mathrm{~kW}$ IR Upgrade FEL

* Corresponding author: Tel: 1-757-269-6862;

fax:1-757-269-5519; E-mail address: chgarcia@jlab.org
[5]. There is one electron bunch produced with each laser pulse.

The IR Demo gun was operated at $320 \mathrm{KV} \mathrm{DC}$ and demonstrated $5 \mathrm{~mA} \mathrm{CW}$ at $74.85 \mathrm{MHz}$ (67 pC/bunch), 1/e lifetime of $58 \mathrm{hr}$ and 1/e extracted charge of $618 \mathrm{C}$ from a $0.283 \mathrm{~cm}^{2}$ illuminated area [4]. Its operational drawback was that the operational voltage, initially $350 \mathrm{kV}$ had to be decreased with subsequent photocathode re-cesiations due to field emission when Cs was deposited on the electrode surface as well as on the wafer.

The upgrade version of the gun shown in Fig. 1 incorporates three major improvements: increased pumping for better vacuum, UHV motion mechanisms for photocathode performance and reliability, and a new method for depositing Cs on the photocathode inside the ball cathode for high voltage operation reliability.

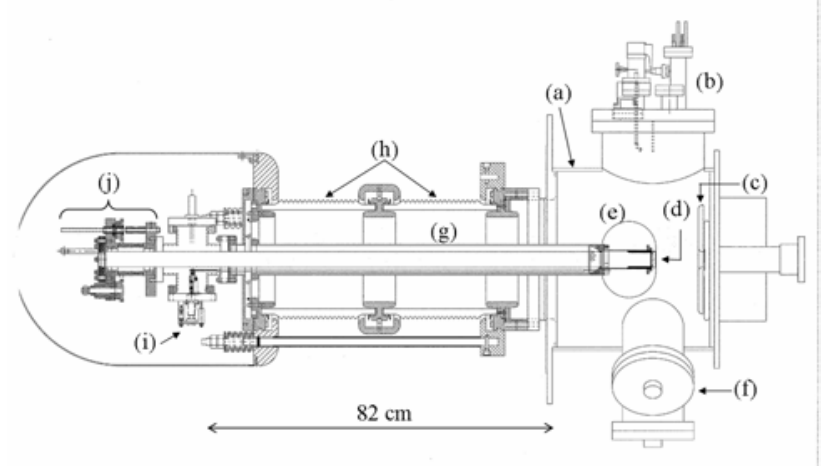

Figure 1: DC photocathode gun schematic. (a) vacuum chamber, (b) instrumentation, (c) anode, (d) photocathode, (e) ball cathode, (f) NEG pumps, (g) ball support tube, (h) ceramics, (i) shield door actuator mechanism, and (j) stalk retracting mechanism.

For vacuum improvement, the internal walls of the chamber were electro-polished and vacuum fired to $600 \mathrm{C}$ to decrease the hydrogen load in the bulk material. The chamber holds two $40 \mathrm{l} / \mathrm{s}$ ion pumps and thee $1300 \mathrm{l} / \mathrm{s}$ SAES NEG pumps placed around the ball-anode gap.

To solve the major problem in the IR Demo gun of spraying Cs on the surface of the ball cathode, two SAES Cs channels were mounted inside the ball cathode to replace the $\mathrm{Cs}$ dispenser under the anode plate. This meant that the photocathode had to be retracted inside the ball during activation and re-cesiation. The stalk holding the photocathode at one end can be manually retracted by means of a gear mechanism located at the back end of the gun (see Fig. 1). Bellows connect a flange welded to the back-end of the stalk with a 6-way cross fixed to the main body of the chamber for vacuum preservation during the translation motion. The stalk slides inside the ball support 
tube on a set of three sapphire rollers mounted on each of two rings. One ring is mounted in the back-end of the support tube, and the other at the opposite end where the tube attaches to the ball cathode. With the stalk in the retracted position, the distance between the photocathode and the Cs channels is $3 \mathrm{~cm}$ for activation. A swing shield door was also incorporated inside the ball cathode to protect the wafer from damage by back-ion bombardment during high voltage conditioning (see Experimental techniques and procedures section below). The shield door is then swung back out of the way of the stalk for regular operations. Figure 3 shows an internal view of the ball cathode with the stalk in the retracted position, the location of the Cs channels and the two positions of the shield door.

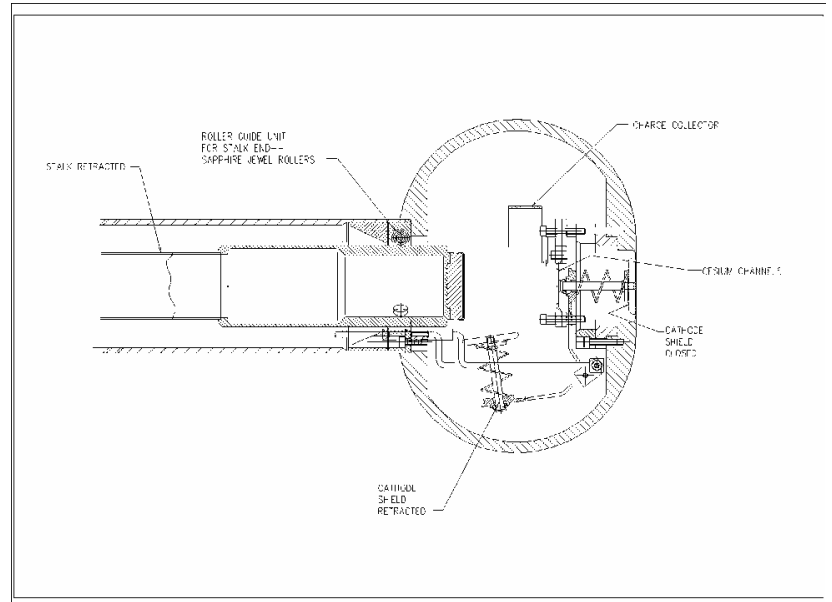

Figure 2: Detail of the inside of the ball cathode with the stalk retracted. The shield door is closed only during high voltage conditioning.

The shield door is actuated by a mechanism mounted on one of the flanges in the 6 way cross (see Fig. 1). This mechanism comprised of a long stainless steel rod 1/16" thick and linkages with sapphire bearings that can retract or move the door into the photocathode position (see Fig. 2 ). The space below the anode plate was no longer needed for the Cs dispenser and allowed the design space to drop the anode plate to the bottom of the chamber effectively moving the solenoid closer to the anode. Correctors were also placed inside the solenoid to help improve beam steering near the photocathode.

\section{EXPERIMENTAL TECHNIQUES AND PROCEDURES}

\section{Wafer preparation and installation}

The photocathode bulk material is a $\mathrm{Zn}$-doped GaAs single crystal wafer $3.18 \mathrm{~cm}$ in diameter. The exposed area of the wafer is through a $2.54 \mathrm{~cm}$ diameter aperture on the ball cathode. The wafer is mounted on a molybdenum disk brazed to the front end of the stalk, which is then installed in a dedicated vacuum chamber for wafer heat and hydrogen cleaning [6]. The temperature and the duration of the heat and hydrogen clean cycle have been optimized for the larger mass of the FEL gun stalk [4]. After the stalk cools down to room temperature, it is removed from the hydrogen clean chamber and transported in a nitrogen atmosphere for its installation in the FEL gun.

\section{Vacuum procedures}

The entire assembly of the upgrade gun except for the stalk with the wafer was performed in a clean room class 1000 environment before being transported to the FEL vault for installation in the injector. Once the stalk was installed in the gun and a rough vacuum established, the NEG pumps were activated to $500 \mathrm{C}$ for $45 \mathrm{~min}$. A standard vacuum bake followed at $250 \mathrm{C}$ until there was less than $10 \%$ drop in the pressure observed in 24 hours. The pressure was monitored during the bake cycle by the bake ion pump current. Later the pressure at room temperature was measured with an extractor gauge, and the vacuum quality monitored with an RGA.

\section{Electrode high voltage conditioning}

Once the final vacuum pressure was achieved after the bake cycle, the gun electrodes were high voltage conditioned to prevent high voltage breakdown and to minimize field emission [7]. Although the nominal voltage of the gun is $350 \mathrm{kV}$, the electrodes were conditioned to $420 \mathrm{kV}$ for reliability during normal operating conditions. At $350 \mathrm{kV}$, the gradient at the photocathode is $4.2 \mathrm{MV} / \mathrm{m}$ and peaks at $8.7 \mathrm{MV} / \mathrm{m}$ on the support tube nearest to the ground end ring (see Fig. 1). Gas desorption [8] was observed starting at $300 \mathrm{kV}$ during the conditioning process, which took about 80 hours to complete. To protect the wafer during the high voltage conditioning, the stalk was retracted and the swing shield door positioned in place of the wafer. The door is used in this position only during high voltage conditioning.

\section{Photocathode activation}

The GaAs wafer, retracted inside the ball cathode, is heat cleaned under vacuum to approximately $550 \mathrm{C}$ for a few hours by means of an electric heater that slides inside the stalk against the back of the molybdenum disk. Once the wafer cools down to room temperature, it is activated following standard techniques [9]; cesium is deposited by heating Cs dispenser channels with electrical current and $\mathrm{NF}_{3}$ is applied using a leak valve [10,11]. During activation, the wafer is illuminated with a white light and photocurrent is monitored using a biased ring anode inside the ball electrode (see Fig. 2). After activation the photocathode is pushed forward to its operational position against the aperture in the ball cathode. A quantum efficiency map of the photocathode is generated with a scanner [12]. The quantum efficiency can be replenished by simply retracting the photocathode inside the ball and running the Cs channels until the QE peaks and drops to about $15 \%$ of the peak value, this process is called recesiation. With the $\mathrm{Cs}$ being applied inside the ball cathode, only the photocathode needs to be high voltage conditioned, which takes about two hours. 


\section{PHOTOCATHODE PERFORMANCE}

In the upgrade gun, two GaAs wafers have been installed to date. During operation using the first photocathode, opportunities to improve gun performance were identified, namely the beamtube drift space downstream of the gun was NEG-coated and the edge of the second wafer was anodized. The differences between operating conditions of the two periods will be described in more detail below.

The first wafer mounted in the gun during the original installation into the FEL vault was activated into a photocathode a total of 12 times during one year starting in May 2003 averaging 3 re-cesiations per activation. Typical quantum efficiencies around 5\% were routinely achieved during activations. A total of 1300 Coulombs were extracted from this wafer with a maximum of 100 Coulombs per re-cesiation. 100 Coulombs of extracted charge represents 5.6 hours of $5 \mathrm{~mA} \mathrm{CW}$ beam time. With this wafer the upgrade gun demonstrated $9.1 \mathrm{~mA} \mathrm{CW}$ beam with $122 \mathrm{pC}$ per bunch at $75 \mathrm{MHz}$ rep rate. It also demonstrated pulsed operation with $8 \mathrm{~mA}$ per pulse and $110 \mathrm{pC} /$ bunch in $16 \mathrm{~ms}$-long pulses at $2 \mathrm{~Hz}$ rep rate. Re-circulation of CW current in the FEL was limited by beam halo generated by the photocathode. During high average current operations significant vacuum rises were observed in the gun chamber and the downstream beam pipe limiting the photocathode lifetime. Beam halo also induced frequent RF arc trips on the injector accelerating cryounit causing gas outbursts that totally depleted the photocathode quantum efficiency in several occasions.

Several steps were taken to reduce halo and improve the photocathode lifetime. In May 2004 a new wafer was installed, additional pumping downstream of the gun chamber was added to the beam pipe, and the drive laser optical transport system was cleaned up to reduce scattered light that contributes to beam halo when it illuminates parts of the photocathode outside the drive laser spot. After the vacuum bake cycle the background pressure measured by the extractor gauge was 3E-11 Torr corrected for hydrogen. The RGA reported $99.9 \%$ hydrogen at 4E-11 Torr with correction. The outermost part of this wafer was anodized using an off-center mask $1.8 \mathrm{~cm}$ in diameter to reduce the active area of the photocathode for further beam halo reduction. The drive laser spot is $0.8 \mathrm{~cm}$ in diameter $\left(0.5 \mathrm{~cm}^{2}\right)$. The anodized wafer has been activated into a photocathode two times since its installation. The improvement in the performance of the upgrade gun with the first photocathode on the anodized wafer delivered about 1000 Coulombs with 6 recesiations in six months. The extracted charge increased to $200 \mathrm{C}$ per re-cesiation and the initial QE increased to $6 \%$. Routinely $96 \%$ of the previous QE was recovered after each re-cesiation.

A second activation was performed on the anodized wafer. This time the initial QE was 7\% and 500 Coulombs were extracted before the first re-cesiation was needed, almost four months later. The increase in the delivered charge and the lifetime can certainly be attributed to a significant decrease in beam halo and improved vacuum conditions. A minute leak was detected in the gun gate valve flange and fixed shortly after the second activation leading to better vacuum. A Coulomb Archiver is software developed by the JLab FEL Instrumentation and Controls Group. It registers in real time the operating conditions of the gun and reads the current from the FEL re-circulation beam dump current monitor. The Archiver has recorded 50 Coulombs in 131 hours of pulse beam, and 450 Coulombs in 44 hours of CW beam from this second activation on the anodized wafer. Preparations are in progress to perform 1/e QE lifetime and 1/e extracted charge studies.

\section{CONCLUSIONS}

The JLab 10kW Upgrade IR FEL DC photocathode gun has demonstrated $9 \mathrm{~mA}$ average electron beam current and reliable high voltage operation after improvements in vacuum and to its mechanical designs. The robustness and exceptional electron beam characteristics have made this type of gun the choice for the development of three currently funded, 100-mA class ERLs as the next generation of FELs and light sources.

\section{ACKNOWLEDGMENTS}

This work supported by the Office of Naval Research, the Joint Technology Office, NAVSEA PMS-405, the Air Force Research Laboratory, U.S. Night Vision Lab, the Commonwealth of Virginia, and by DOE Contract DEAC05-84ER40150.

\section{REFERENCES}

[1] C. Hernandez-Garcia, et al., 26th. International Free Electron Laser Conference, Trieste, Italy, 558, (2004).

[2] L. Merminga, D. R. Douglas, and G. A. Krafft, Annu. Rev. Nucl. Part. Sci. 53, 387 (2003).

[3] G. R. Neil and L. Merminga, Rev. Mod. Phys. 74, 685 (2002).

[4] T. Siggins, et al., Nucl. Instrum. Methods Phys Res., Sect. A 475, 549 (2001).

[5] D. Douglas, JLAB-TN-99-019, 21 July, 1999.

[6] C. K. Sinclair, B. M. Poelker, and J. S. Price, 1997 Particle Accelerator Conference, Vancouver, B.C. Canada, 2864, (1997). IEEE, Piscataway, NJ, (1998).

[7] F. R. Schwirzke, IEEE Trans. Plasma Sci. 19, 690 (1991).

[8] W. T. Diamond, J. Vac. Sci. Technol. A 16 (2), 720 (1998).

[9] D.T. Peirce and F. Meier, Phys. Rev. B 13 (12), 5484 (1976).

[10] C. K. Sinclair, AIP Conf. Proc. 156, 298 (1986).

[11] D. Engwall, et al., 1997 Particle Accelerator Conference, Vancouver, B.C. Canada, 2693, (1997). IEEE, Piscataway, NJ, (1998).

[12] J. Gubeli, et al., Nucl. Intrum. Methods Phys Res., Sect. A 475, 554 (2001). 